\title{
Production of rhamnolipids by Pseudomonas aeruginosa growing on carbon sources
}

\author{
${ }^{1 *}$ H. Rashedi ${ }^{2}$ M. Mazaheri Assadi, ${ }^{1}$ E. Jamshidi and ${ }^{1}$ B. Bonakdarpour \\ ${ }^{1}$ Faculty of Chemical Engineering, Amir Kabir University, Tehran, Iran \\ ${ }^{2}$ Biotechnology Center, Iranian Research Organization for Science and Technology, Tehran, Iran \\ Received 16 October 2005; revised 7 January 2006; accepted 15 March 2006; available online 25 June 2006
}

\begin{abstract}
Arhamnolipid producing bacterium, Pseudomonas aeruginosa was previously isolated from Iranian oil over years. Isolated strain was identified by morphological, biochemical, physiological and 16 sr RNA (1). Glycolipid production by isolated bacterium using sugar beet molasses as a carbon and energy source was investigated. Biosurfactant production was quantified by surface tension reduction, Critical Micelle Dilution (CMD), Emulsification Capacity (EC), and Thin Layer Chromatogeraphy. biosurfactants during growth on waste Dates as the primary carbon and nitrogen sources, respectively. After $48 \mathrm{~h}$ of growth the culture supernatant fluid had a rhamnose concentration of 0.18 $\mathrm{g} / \mathrm{L}$ and surface tension was reduced to $20 \mathrm{mN} / \mathrm{m}$ ( \%). (reduced the interfacial tension against crude oil from $21 \mathrm{mN} / \mathrm{m}$ to $0,47 \mathrm{mN} / \mathrm{m}$ ) Result from the study showed that the growth of the bacteria using molasses as carbon sources is growthassociated. The specific production rate of rhamnolipid with $2 \%, 4 \%, 6 \%, 8 \%$ and $10 \%$ of molasses are $0.00065 ; 4.556$; 8.94; 8.85; and 9.09. respectively The yield of rhamnolipid per biomass with $2 \%, 4 \%, 6 \%, 8 \%$ and $10 \%$ molasses are $0.003 ; 0.009 ; 0.053 ; 0.041$ and 0.213 respectively. The production of rhamnolipid $(0.0531 \mathrm{~g}$ rhamnolipid/g biomass) is higher compare to the culture grown in aerobic condition ( $0.04 \mathrm{~g}$ rhamnolipid/g biomass). The rhamnolipids were able to form stable emulsions with n-alkanes, aromatics, crude oil and olive oil. These studies indicate that renewable, relatively inexpensive and easily available resources can be used for important biotechnological processes.
\end{abstract}

Key words: Pseudomonas aeruginosa, biosurfactant, waste dates, sugar beet molasses

\section{INTRODUCTION}

Surfactants and emulsifiers are widely used in the petroleum, pharmaceutical, cosmetic and food industries. Most of these compounds are chemically synthesized and it is only in the past few decades that surface-active molecules of biological origin have been described. At present biosurfactants are readily biodegradable and can be produced from renewable and cheaper substrates, they might be able to replace their chemically synthesized counter parts. (Arino, 1996). Among the heterogeneous group of biosurfactants, the rhamnose-containing glycolipids produced by Pseudomonas. Rhamnolipid has been known as biosurfactant which is produced by Pseudomonas aeruginosa in fermentation process. Several carbon sources such as ethanol, glucose, vegetable oil and hydrocarbon have been used to produce rhamnolipid. In this study, we are trying to use molasses which is a waste product from sugar industry as carbon source

*Corresponding author, Email: rashedi@hcbio.ir

Tel.: +9821-2200 0042; Fax: +9821-2200 0042 to produce rhamnolipid. The bacteria which was previously isolated from Iranian oil over years. Microbial surfactants are generally less toxic and more biodegradable than synthetic surfactants (Desai and Patel, 1994 and Guerra-Santos et al., 1984). Rhamnolipid biosurfactants specifically produced by Pseudomonas aeruginosa have great potential for industrial application (Reiling et al., 1986) and bioremediation (Banat, 1995). Four rhamnolipid analogs, R1-R4, have been isolated (Syldatk et al., 1985a). Rhamnolipid production has been examined with some carbon sources as $n$ paraffin, $n$-tetradecane or glucose (Syldatk et al., 1985b and Robert et al., 1989) and plant oil was also good carbon, source. Waste Dates is an attractive raw carbon source for microbial production of a variety of biochemicals (Juzlová et al., 1994). Pseudomonas BOP 100 has the capabilities for production of rhamnolipid and phenazine when grown on Waste Dates as sole carbon source (Osman et al., 1996). In this paper, we describe the production of rhamnolipid 
by fed-batch culture using Waste Dates as sole carbon. Almost all surfactant currently in use are chemically derived from petroleum. however interest in microbial surfactant has been steadily increasing in recent years due to their diversity ,environmentally friendly characteristics, the possibility of their production through fermentation and their potential application in such areas as the environmental protection, surplus crude oil recovery, health care and the food processing industries. Therefore, it is necessary to know more about the producing microorganism's physiology and the process engineering to develop the technology for these production of molecules, the use of cheap substrates being of utmost importance. Interest in microbial surfactants has increased considerably in recent years, especially due to their potential application in enhanced oil recovery. The production of surfaceactive compounds by microorganisms is well established and has been a matter of discussion at different international meetings. Their potential for enhanced oil recovery is based on their application as agents for rock wetting, micellar flooding, emulsification, deemulsification, and viscosity reduction of heavy crude oils. The specific production rate and yield of rhamnolipid are explained as following: Growth associated specific production rate:

$$
\begin{aligned}
& Q p=Y_{P / X} \bullet \mu \\
& Y_{P / X}=\frac{P 2-P 1}{X 2-X 1}
\end{aligned}
$$

Mixed-growth associated specific production rate

$$
Q_{p}=Y_{P / x} \bullet \mu+\beta
$$

$\mathrm{Qp}=$ specific production rate of rhamnolipid (g/L.h)

$\mathrm{Yp} / \mathrm{x}$ = yield of rhamnolipid

$\mu=$ specific growth rate $(1 / \mathrm{h})$

$\mathrm{P}=$ rhamnolipid concentration $(\mathrm{g} / \mathrm{L})$

$\mathrm{X}=$ biomass concentration $(\mathrm{g} / \mathrm{L})$

â =production rate during stationary phase (g/L.h)

\section{MATERIALS AND METHODS}

Identification of the microorganism

The microorganism was isolated from oil wells in the southern of Iran. The method of serial dilutions of the sample and plate count in selective medium Cetrimide agar was used for isolation purposes. The plates were incubated at $30^{\circ} \mathrm{C}$ for $48 \mathrm{hr}$. The strain was activated in a triptic soyer agar medium (TSA), cultivated at $300^{\circ} \mathrm{C}$ for $48 \mathrm{~h}$ and transferred to a $250 \mathrm{~mL}$ flask, containing 50 $\mathrm{mL}$ of TSA. The flask was incubated at $300{ }^{\circ} \mathrm{C}$ and 250 rpm during $20 \mathrm{hr}$. (shaker, Gallenkamp, England) Cells were havested by centrifugation at $6000 \mathrm{rpm}$ during 20 minutes. (centrifuge, Shimadzu,Japan,). The centrifuged microbial mass was suspended in a culture medium (medium salt production - MSP) with the following composition (g/L): (NH4)2SO, 1.0 ; $\mathrm{KH}_{4} \mathrm{PO}_{4}$, 3.0 ; $\mathrm{MgSO}_{4} .7 \mathrm{H}_{2} 0,0.2$. The $\mathrm{pH}$ was adjusted to 7.0 with a solution of $\mathrm{KOH}(1 \mathrm{~N})$ plus $1 \% \mathrm{v} / \mathrm{v}$ of glycerol P.A. (Merck) in order to obtain the initial inoculum concentration of $0.005,0.075$ and $0.1 \mathrm{~g} / \mathrm{L}$, in accordance with a calibration curve of dry weight versus absorbance. The production of rhamnolipids was studied during a seven days incubation period in flasks under agitation with the initial seeding material standardized in a culture medium, as mentioned previously, maintained at a temperature of $30^{\circ} \mathrm{C}$ and stirred in a rotary shaker at $120 \mathrm{rpm}$. The carbon sources used were n-hexadecane paraffin oil collected at flowing wells in the Khark island of Iran, consisting of $32 \%$ saturated hydrocarbons, $23 \%$ aromatics, $36 \%$ of resins and $9.1 \%$ asphaltenes), glycerol (PA-Merck, Darmstadt) and molasses from pak company. In addition to the carbon sources studied, the $\mathrm{C} / \mathrm{N}$ ratio varied with the following concentrations of glycerol: 0.5, 1, 2, 3, 4, 5 and $6 \% \mathrm{v} / \mathrm{v}$, corresponding to $\mathrm{C} / \mathrm{N}$ ratios of $20,40,60$, 80,100 table and 120 . For evaluation of the most appropriate nitrogen sources for the production of biosurfactants, $\mathrm{NaNO}_{3},\left(\mathrm{NH}_{4}\right)_{2} \mathrm{SO}_{4}$ and $\mathrm{CH}_{4} \mathrm{~N}_{2} \mathrm{O}$ were employed at the following concentrations: 1.45, 1.0, and $0.51 \mathrm{~g} / \mathrm{L}$ and glycerol 3\% v/v. rhamnolipid assay: 1 $\mathrm{mL}$ of culture broth was extracted with $1 \mathrm{~mL}$ of chloroform/methanol (1:1, v/v) mixture and the organic phase was analyzed by TLC on silica gel 60 F254 plate using a solvent of chloroform/methanol/water (65:25:4). Rhamnolipid spots were detected by orcinol reagent and quantified by the density (area) at $550 \mathrm{~nm}$ in the reflection mode with a TLC scanner. Glucose was used as a standard instead of rhamnolipid as described previously (Singer and Finnerty, 1990). In this assay, 1 mg rhamnolipid corresponded to $0.17 \mathrm{mg}$ glucose. HPLC was carried out using a Shodex GS-310 (7.6 mm 250 $\mathrm{mm}$ ) gel filtration column. Mobile phase used was $30 \mathrm{v} /$ $\mathrm{v} \%(\mathrm{v} / \mathrm{v})$ methanol, run at $0.3 \mathrm{~mL} / \mathrm{min}$ and monitored at $203 \mathrm{~nm}$. Five $\mathrm{mL}$ of suitably diluted samples were injected. Retention time of rhamnolipid R1 and R2 was $15.1 \mathrm{~min}$ and $15.8 \mathrm{~min}$, respectively. Waste Dates consumption during fermentation was assayed 
according to the method as described previously (Nakata et al., 1995).

\section{Biomass Concentration}

Bacterial growth was monitored by measurement of absorbance at a wave length of $610 \mathrm{~nm}$. Samples of 50 $\mathrm{mL}$ were removed from the flasks at regular intervals and centrifuged at $6000 \mathrm{rpm}$ for $15 \mathrm{~min}$. The centrifuged cells were suspended in $5 \mathrm{~mL}$ of distilled water and the biomass, expressed in dry weight (g/L), was obtained from a calibration curve.

Quantification of Rhamnose and Glycerol: The quantification of rhamnolipids expressed in rhamnose (g/L) was measured in the cell free culture medium, using the phenol sulfuric acid method. Glycerol was assessed by the enzymatic colorimetric method for triglyceride content evaluation.

Determination of the Critical Micelle Concentration (CMC): The surface tension of the biosurfactant was measured by the ring method using a CSC-Dunouy tensiometer (cole parmer instrument Co., Bunker, IL, U.S.A) at room temperature. The concenteration at which micelles began to from was represented as the
CMC.At the CMC, sudden changes in surface tension, electrical conductivity and detergency were observed. The CMC was determined by plotting the surface tension as a function of the biosurfactant concentration and surface tension at this point was designated as CMC.

\section{RESULTS}

Biosurfactant production was studied using medium A, with \% molasses ( $\mathrm{v} / \mathrm{v})$ varying concentrations of molasses being used as the sole source of carbon. The biosurfactant production increased with the increase in the concentration of molasses and maximum production occurred when $7 \%(\mathrm{v} / \mathrm{v})$ of molasses were used (Figs. 1 and 2).

Table 1: Relation between molasses concenteration and specific production rate

\begin{tabular}{cc}
\hline Molasses & Qp (g/L.h) \\
\hline $2 \%$ & 0.00065 \\
$4 \%$ & 4.555674 \\
$6 \%$ & 8.941563 \\
$8 \%$ & 8.850229 \\
$10 \%$ & 9.092182 \\
\hline
\end{tabular}

Table 2: Effect of carbon source on rhamnolipid production

\begin{tabular}{cccc}
\hline Carbon source $(\mathrm{g} / \mathrm{L})$ & Cell dry mass (g/L) & $\begin{array}{c}\text { Rhamnolipid (R1) } \\
\text { (g/cell dry mass) }\end{array}$ & $\begin{array}{c}\text { Rhamnolipid (R2) } \\
\text { (g/cell dry mass) }\end{array}$ \\
\hline ethanol & 0.9 & 2.2 & 1.8 \\
glucose & 7.1 & 0.030 & 0.010 \\
sucrose & 0.4 & 0 & 0 \\
maltose & 0.4 & 0 & 0 \\
glycerol & 0.4 & 0.8 & 0.8 \\
dates & 5.2 & 0.4 & 0.5
\end{tabular}

Culture condition: $30 \mathrm{~g} / \mathrm{L}$ carbon source, $5 \mathrm{~g} / \mathrm{L}$ yeast extract, $5 \mathrm{~g} / \mathrm{L}$ Dates, $1 \mathrm{~g} / \mathrm{L} \mathrm{K}_{2} \mathrm{HPO}_{4}, 0.5 \mathrm{~g} / \mathrm{L}$ $\mathrm{Mg} \mathrm{SO}_{4}, 7 \mathrm{H}_{2} \mathrm{O}, \mathrm{pH} 7$ cultivative at $28{ }^{\circ} \mathrm{C}$

Table 3: Effect of nitrogen source on rhamnolipid production

\begin{tabular}{lccc}
\hline Nitrogen source(g/L) & Cell dry mass(g/L) & $\begin{array}{c}\text { Rhamnolipid( R1) } \\
\text { (g/cell dry massg) }\end{array}$ & $\begin{array}{c}\text { Rhamnolipid (R2) } \\
\text { (g/cell dry massg) }\end{array}$ \\
\hline Dates & 2.5 & 0.4 & 0.2 \\
Yeast extract & 1.5 & 0.7 & 0.5 \\
(NH4)2So4 & 0 & 0 & 0 \\
NH4NO3 & 0 & 0 & 0 \\
Malt extract & 0 & 0 & 0 \\
\hline
\end{tabular}

Culture condition: $3 \mathrm{v} / \mathrm{v} \%$ ethanol, $5 \mathrm{~g} / \mathrm{L}$ nitrogen source, $1 \mathrm{~g} / \mathrm{L} \mathrm{K}_{2} \mathrm{HPO}_{4}, 0.5 \mathrm{~g} / \mathrm{L}$

$\mathrm{Mg} \mathrm{SO}_{4}, 7 \mathrm{H}_{2} \mathrm{O}, \mathrm{pH} 6.8$ cultivative at $28^{\circ} \mathrm{C}$ for 7 days. 
H. Rashedi, et al.

Table 4: Combination effect of yeast extract and other nitrogen source on rhamnolipid production

\begin{tabular}{|c|c|c|c|c|c|c|c|c|c|c|}
\hline & & \multicolumn{9}{|c|}{ Rhamnolipid } \\
\hline & & \multicolumn{3}{|c|}{ Dates } & \multicolumn{3}{|c|}{ CSL } & \multicolumn{3}{|c|}{ Poly pepton } \\
\hline \multirow{4}{*}{ Yeast extract } & & $2 \mathrm{~g} / \mathrm{L}$ & $5 \mathrm{~g} / \mathrm{L}$ & $10 \mathrm{~g} / \mathrm{L}$ & $2 \mathrm{~g} / \mathrm{L}$ & $5 \mathrm{~g} / \mathrm{L}$ & $10 \mathrm{~g} / \mathrm{L}$ & $2 \mathrm{~g} / \mathrm{L}$ & $5 \mathrm{~g} / \mathrm{L}$ & $10 \mathrm{~g} / \mathrm{L}$ \\
\hline & $2 \mathrm{~g} / \mathrm{L}$ & 2.7 & 2.8 & 1.1 & 1.8 & 2.3 & 1 & 0 & 0 & 0 \\
\hline & $5 \mathrm{~g} / \mathrm{L}$ & 3 & 3.7 & 2.5 & 2.8 & 0.2 & 0.003 & 0 & 0.5 & 0.7 \\
\hline & $10 \mathrm{~g} / \mathrm{L}$ & 1.5 & 1.8 & 1.9 & 0.2 & 0 & 0.04 & 0 & 0 & 0 \\
\hline
\end{tabular}

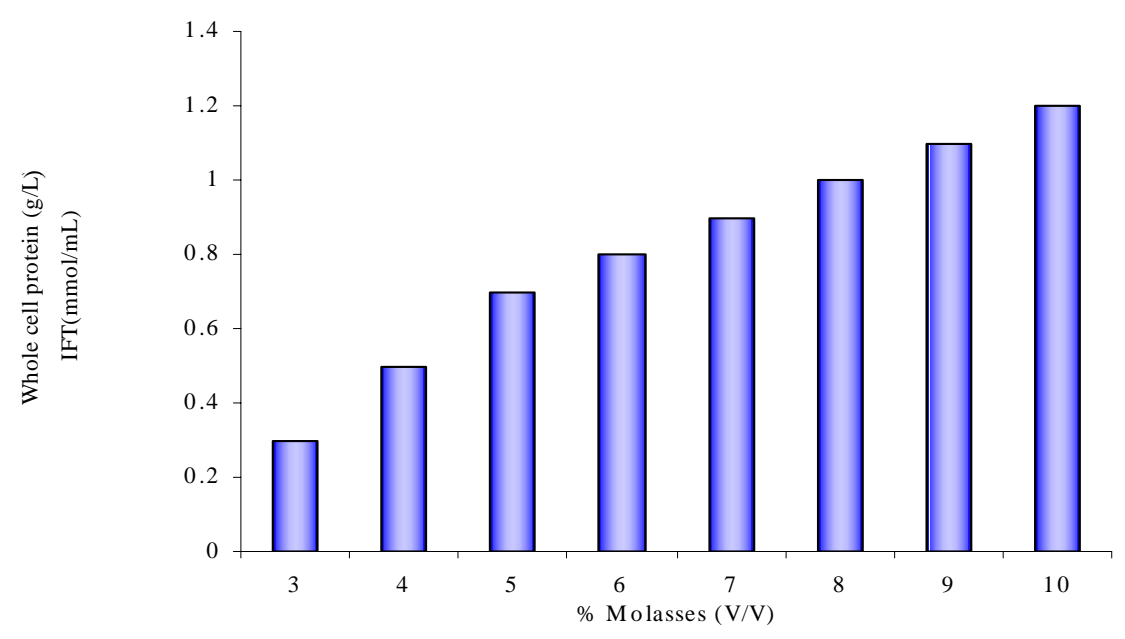

Fig. 1: Effect of concenteration of molasses on surfactant production were IFT between medium and crude oil was $21 \mathrm{mmol} / \mathrm{lm}$

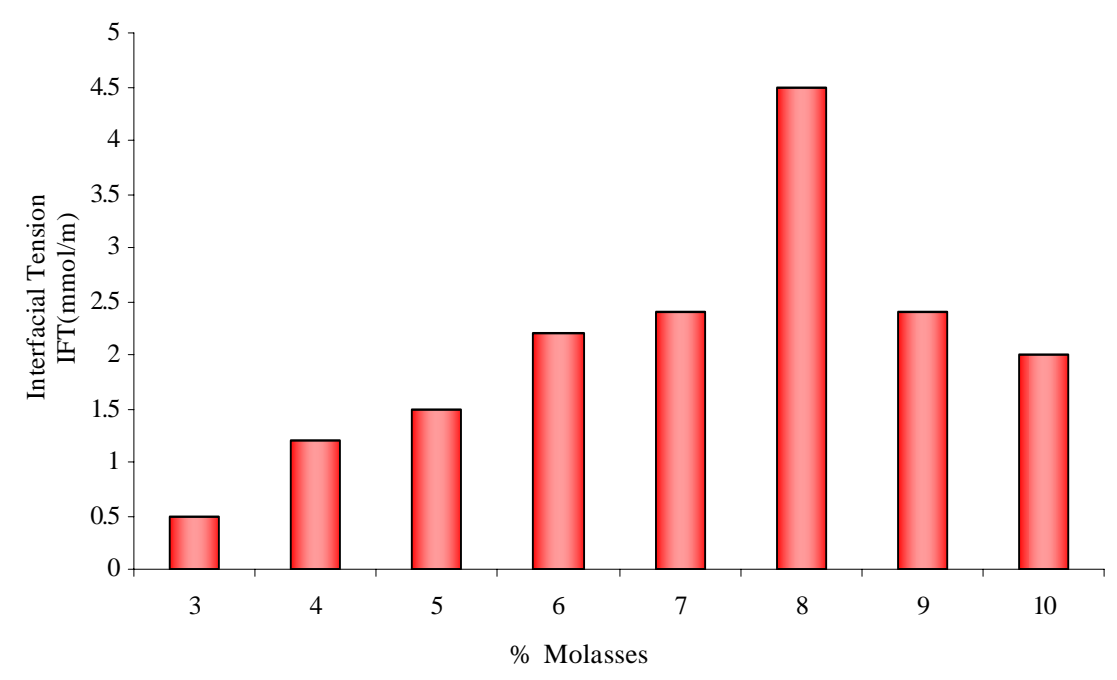

Fig. 2: Effect of concenteration of molasses on surfactant production were estimatated after $96 \mathrm{~h}$ of incubation IFT between medium and crude oil was $21 \mathrm{mmol} / \mathrm{lm}$ 


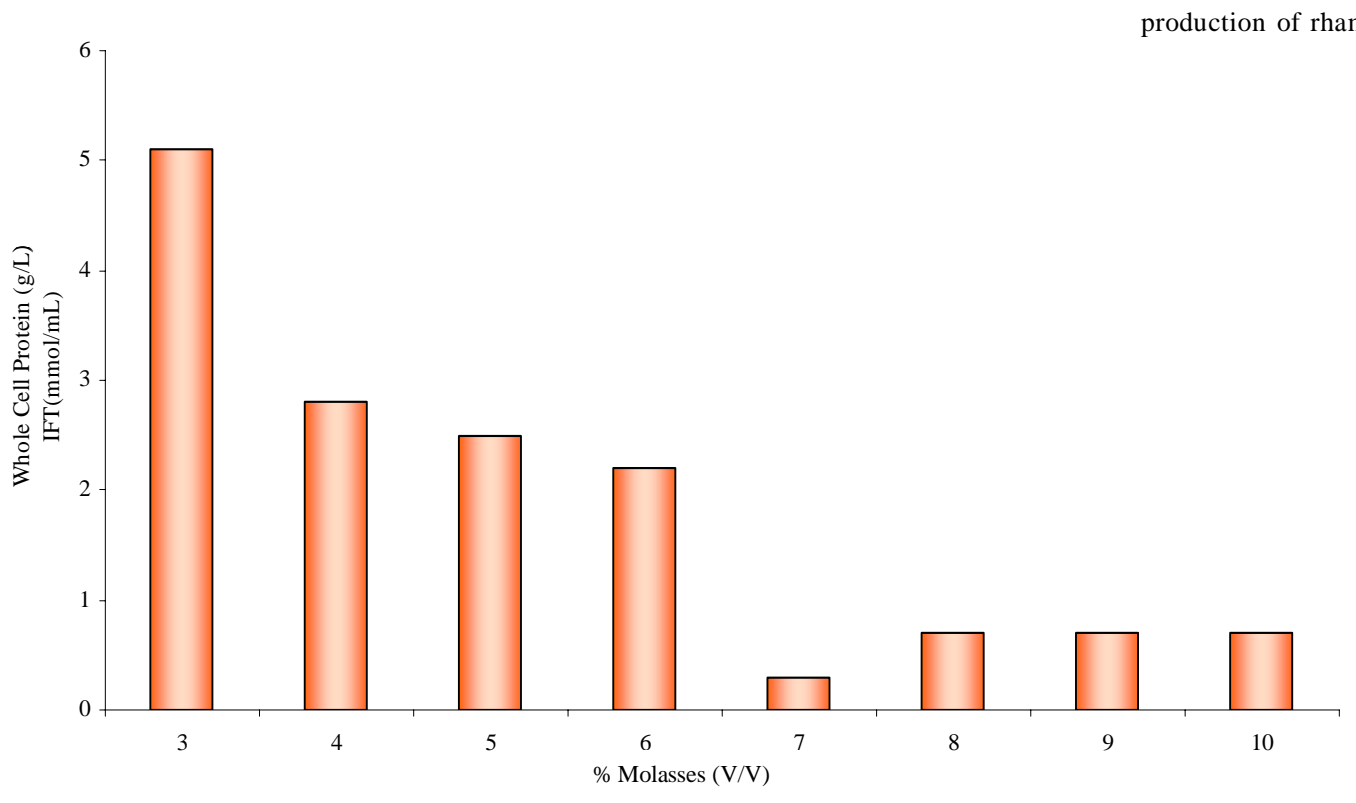

Fig. 3: Effect of concenteration of molasses on surfactant production were estimatated after $96 \mathrm{~h}$ of incubation IFT between medium and crude oil was $21 \mathrm{mmol} / \mathrm{lm}$

Further increase in the concentration of molasses did not affect surfactant production significantly. However, the biomass increased with the increase in the concentration of molasses, as evident from the whole cell protein. (Fig.3). The increase in subtrate concentration (S) will result in the increase of specific growth rate $(\mu)$. This result can be seen in Fig. 2. Table 1 shows that the specific production rate of rhamnolipid (Qp) also related to the increase of subtrate concentration (S).

Effect of carbon and nitrogen source on rhamnolipid production

The experiments were conducted in the fermentation medium containing $3 \mathrm{v} / \mathrm{v} \%$ waste dates and $5 \mathrm{~g} / \mathrm{L}$ nitrogen source (Table 2). The effect of nitrogen source in production of rhamnolipid are shown (Table 3). Since yeast extract enhanced rhamnolipid production during early cultivation by 4 days , the effect of yeast extract plus other nitrogen source were examined (Table 4). The combination effect was the highest when soy flour was used as a pair of nitrogen sources. The optimal rhamnolipid production, 3.7 $\mathrm{g} / \mathrm{L}$, was obtained when yeast extract and soy flour were added $5 \mathrm{~g} / \mathrm{L}$ each in 3\% (v/v) Waste Dates medium.

Effect of waste dates feeding on rhamnolipid production

More than 3\% (v/v) Waste Dates was toxic for growth of this strain. Therefore, we examined the effect of intermittent feeding of Waste Dates on rhamnolipid production using a fermentation medium containing 5 g/L each of yeast extract and soy flour (Fig. 1). Growth and rhamnolipid increased gradually in parallel for 7 day cultivation. Waste Dates was completely consumed at 7 days. Thirty two gram rhamnolipid/L was finally obtained from a total of 55.3 g Waste Dates/L. Substrate conversion rate was $58 \%$.

\section{Isolation and identification of rhamnolipids}

The culture broth $(450 \mathrm{~mL})$ was centrifuged after adjusted to $\mathrm{pH}$ 3.0. The supernatant was applied to aDEAE-Toyopearl 650M column $(2.548 .5 \mathrm{~cm})$ equilibrated with $0.5 \mathrm{M}$ Tris-HCl buffer ( $\mathrm{pH} 9.0$ ). After washed with the buffer, the column was eluted with a linear gradient of $0-0.4 \mathrm{M} \mathrm{NaCl}$ in $0.5 \mathrm{M}$ Tris-HCl buffer (pH 9.0). A flow rate was $2.3 \mathrm{~mL} / \mathrm{min}$ and $7 \mathrm{~mL}$ each was fractionated, followed by rhamnolipid detection. The active fractions contained rhamnolipid R1 and R2 were pooled and extracted with equal volume of chloroform/ methanol $(1: 1, \mathrm{v} / \mathrm{v})$ and the organic layers were evaporated to dryness. The recoveries of R1 and R2 from this chromatography were $91.5 \%$ and $89.8 \%$, respectively. These compounds thus obtained were identified as rhamnolipid R1 and R2, by $1 \mathrm{H}-\mathrm{NMR}$ and FAB mass analyses.

\section{DISCUSSION AND CONCLUSION}

Rhamnolipid production by Pseudomonas aeruginosa has been found to be affected by nutrient sources, 
especially carbon sources in medium. Water soluble carbon sources such as glucose could be used for rhamnolipids production (Syldatk et al., 1985a), but water insoluble materials like alkane and oil are superior to them. It has been thus thought that the microorganism produces rhamnolipids to emulsify these water insoluble carbon sources for well assimilation. Nitrogen limitation caused an overproduction of rhamnolipids (Syldatk et al., 1985b) and the importance of $\mathrm{C} / \mathrm{N}$ ratio in medium on rhamnolipid production (Guerra-Santos et al., 1984). The production of rhamnolipids was studied during a seven day fermentation period in flasks under agitation with the initial seeding material standardized in a culture medium, as mentioned previously, maintained at a temperature of $30{ }^{\circ} \mathrm{C}$ and stirred in a rotary shaker at $120 \mathrm{rpm}$. The carbon sources used were $\mathrm{N}$-hexadecane (Merck, Darmstadt), paraffinic oil collected at flowing, glycerol (PA - Merck, Darmstadt). In addition to the carbon sources studied, the $\mathrm{C} / \mathrm{N}$ ratio varied with the following concentrations of glycerol: 0.5, 1, 2, 3, 4, 5 and $6 \% \mathrm{v} / \mathrm{v}$, corresponding to $\mathrm{C} / \mathrm{N}$ ratios of $20,40,60$, 80,100 and 120 . For evaluation of the most appropriate nitrogen sources for the production of biosurfactants, $\mathrm{NaNO}_{3},\left(\mathrm{NH}_{4}\right)_{2} \mathrm{SO}_{4}$ and $\mathrm{CH}_{4} \mathrm{~N}_{2} \mathrm{O}$. According to their data, the optimum $\mathrm{C} / \mathrm{N}$ ratio was 18 and rhamnolipids were no longer produced at the $\mathrm{C} / \mathrm{N}$ ratio less than 11 .Our results with rhamnolipid production by Pseudomonas aeruginosa HR revealed that Waste Dates gave the highest productivity (4 g/cell dry mass g) among several carbon sources tested (Table 1). Considering necessity of separation process of rhamnolipid from oil on recovery, it is clear that Waste Dates is superior to rape seed oil for rhamnolipid production. We achieved marked improvement in the yield by intermittent feeding of Waste Dates. Among some intermittently fed experiments tested, the result shown in Fig. 1 was best for rhamnolipid production. In our results, optimal nitrogen sources were a combination of $5 \mathrm{~g} / \mathrm{L}$ yeast extract (Table 3 ). The $\mathrm{C} / \mathrm{N}$ ratio was less than 3 in an non-feeding culture, but more than 50 in the feeding culture. This may be one of reasons why the feeding culture produces a considerable amount of rhamnolipids.

\section{REFERENCES}

Andre C. , Espuny, M. J., Robert, M. , Mercade, M. E., Manrresa, A., Guinea, J. and Leeuwenhoek A.V., (1998). Physicochemical characterization and antimicrobial properties of rhamnolipids produced by Pseudomonas aeruginosa 47T2 NCBIM 40044, J. Microbiol., in Press; 81 (3), 316-322.

Arino S. Marchai, R. and Van Decasteel, J. P., (1996). Identification and Production of a Rhamnolipidic Biosurfactant by a Pseudomonas Species , Appl Microbiol. Biotechnol; 45; 162-168.

Artiola, J. F., Ochoa-Loza, F. J. and Maier, R. M., (2001). Stability Constants for the Complexation of Various Metals with a Rhamnolipid Biosurfactant., J. Environ. Qual; 30 (2), 479-85.

Babu, P. S., Vaidya, A. N., Bai, A. S., kapur, R., Juwarkar, A. and Khanna, P., (1996). Kinetics of Biosurfactant, Production by Pseudomonas aeruginosa Strain BS2 from Industrial Wastes, Biotech. Letters; 18 (3), 263-268.

Bai, G., Mark, L., Brusseau, R. and Miller, M., (1998). Influence of Rhamnolipid Biosurfactants in: Biotechnology; 421-457.

Beeba, J. L. and Umbreit, W. W., (1971). Microbial production of biosurfactants and their importance, J. Bacteriol. 108, 612 .

Burger, M. M., Glaser, L., Burton, R. M., (1998). Biol. Chem.; 238, 2595-2602.

Banat I. M., (1994) Bioresource Technol. 51, 1-12. Desai A. J. and Patel R. M. J. Sci. Ind. Res., 53, 619-629.

Guerra-Santos, L., Käppeli, O. and Fiechter, A. (1984). Appl.Environ. Microbiol. 48, 301-305.

Juzlová, P., Martínková, L., Lozinski, J. and Machek, F., (1994). Enzyme Microb. Technol; 16, 996-1001.

Nakata, K., Hasegawa, J. and Okamura, K. (1995). Biosci., BiotechBiochem., 59, 986-989.

Osman, M., Ishigami, Y., Someya, J. and Jensen, H. B., (1996). Oil Chem. So; 73, 851-856.

Reiling, H. E., Thanei-wyss, U., Guerra-Santos, L. H., Hirt, R., Käppeli O. and Fiechter, A. (1986). Appl. Environ. Microbiol., 51, 985-989.

Robert, M., Mercade, M. E., Bosch, M. P., Parra, J. L., Espuny M. J., Manresa, M. A. and Guinea, J. (1989). Biotech. Lett., 11, 871-874.

Singer, M. E. and Finnerty, (1990). W. R. Can. J. Microbiol., 36, 746-750.

Syldatk, C., Lang, S. and Wagner, F. Z., (1985a). Naturforsch., 40, 51-60.

Syldatk, C., Lang, S., Matulovic, U. and Wagner, F. Z., (1985b). Naturforsch. 40c, 61-67. 
production of rhamnolipids...

\section{AUTHOR(S) BIOSKETCHES}

Rashedi, H., M.Sc., Ph.D., is a secretary manager of Iranian Higher council of Biotechnology , and a Ph.D. Research of biochemical ENG of Faculty of Chemical ENG, Amir Kabir University.Tehran, Iran, Email: Rashedi@hcbio.ir

Mazaheri Assadi, M., M.Sc., Ph.D., is a associate professor in the Department of Biotechnology, Iran Research Organization for Science and Technology Tehran, Iran.

Email:mxmazaheriassadi@yahoo.com

Jamshidi, E., M.Sc., Ph.D., is a Proff of Chemical ENG of Faculty of Chemical ENG, Amir Kabir University.Tehran, Iran .Email: jamshidim@yahoo.com

Bonakdarpour, B., M.Sc., Ph.D., is a associate professor of Chemical ENG of Faculty of Chemical Eng, Amir Kabir University. Tehran, Iran. Email: babakb@aut.ac.ir

\section{This article should be referenced as follows:}

Rashedi, H., Mazaheri Assadi, M., Jamshidi, E., and Bonakdarpour, B., (2006). Production of rhamnolipids by Pseudomonas aeruginosa growing on carbon sources. Int. J. Environ. Sci. Tech., 3 (3), 297-303. 